\title{
PERCEPÇÕES DE TRABALHO E FORMAÇÃO: \\ Tessituras do quefazer com a cultura de paz
}

\author{
Madson Pinto dos Santos \\ Rosária Helena Ruiz Nakashima
}

\section{Resumo}

O presente artigo tem como objetivo perceber relações e equivalências dos temas geradores (trabalho, escola e paz) e suas pertinências para a humanização dos interlocutores da pesquisa. Para esta finalidade fez-se uso da metodologia qualitativa, orientada por princípios da pesquisa participante, tendo como técnica o círculo de cultura, além de um objeto artístico. Os teóricos Freire (2015), Galtung (2003), Delors (2006) e Morin (2011) nos ajudaram a entender que o trabalho e a escola são categorias importantes no movimento dialético para o ser mais, mas um terceiro elemento, a cultura de paz, faz-se necessário para o avançar na humanização de homens e mulheres.

Palavras-chave: educação de jovens e adultos (EJA); pedagogia libertadora; humanização.

\section{PERCEPTIONS OF WORK AND TRAINING: weaving of what-to-makewith the culture of peace}

\begin{abstract}
This article aims to understand relations and equivalences of the generative themes (work, school and peace) and their relevance for the humanization of the research interlocutors. For this purpose, the qualitative methodology was used and guided by principles of participatory research, using the culture circle as a technique, as well as an artistic object. Theorists Freire (2015), Galtung (2003), Delors (2006), and Morin (2011) helped us to understand that work and school are important categories in the dialectical movement being more, but a third element, the culture of peace, it is necessary to advance the humanization of men and women.
\end{abstract}

Keywords: youth and adult education; liberating pedagogy; humanization.

\section{PERCEPCIONES DE TRABAJO Y FORMACIÓN:} tesituras de qué-hacer con la cultura de paz

\section{Resumen}

Este artículo tiene como objetivo comprender las relaciones y equivalencias de los temas generadores (trabajo, escuela y paz) y su relevancia para la humanización de los interlocutores de investigación. Para ello, se utilizó la metodología cualitativa y se guió por principios de investigación participativa, utilizando el círculo cultural como técnica, además de objeto artístico. Los teóricos Freire (2015), Galtung (3003), Delors (2006) y Morin (2011) nos ayudaron a comprender que el trabajo y la escuela son categorías importantes en el movimiento dialéctico para ser más, pero un tercer elemento, la cultura de paz, es necesario avanzar en la humanización de hombres y mujeres.

Palabras clave: educación de jóvenes y adultos; pedagogía liberadora; humanización. 


\section{INTRODUÇÃO}

O presente artigo é resultado de uma pesquisa realizada com uma turma da Educação de Jovens e Adultos (EJA), do $4^{\circ}$ período do $1^{\circ}$ segmento, composta por 10 educandos e sua professora, de uma escola municipal da cidade de Araguaína, Estado do Tocantins, região Norte do Brasil. As discussões apresentadas correspondem ao processo de síntese de temas geradores representados pelas categorias trabalho, escola e paz - que teve em vista os relatos sobre os motivos dos participantes da pesquisa terem desistido de estudar quando mais jovens; o contexto atual que se encontram; e seus sonhos a realizar.

Estão na EJA, portanto, para superar as situações-limite, em busca de melhores condições de trabalho e vida digna. De fato, para quem lida com o ensino, também acredita que é uma das principais soluções, inclusive propagando a formação ao longo da vida, por se tratar de uma forma garantidora da sobrevivência e de dignidade. Contudo, da mesma forma como pode ser um caminho para a liberdade, pode ser também um mecanismo de aprisionamento. Como, então, evitar as armadilhas de uma educação que se configura como bancária, que presta serviços ao opressor e é vendida como benesse para os oprimidos? Visto que não passa de um engodo, dos mais perversos, pois a educação bancária, embora transmissora de conteúdos, não o faz com criticidade e nem habilita os sujeitos à criação, mas somente à reprodução, tornando-se, assim, em um poderoso mecanismo de controle utilizado pela opressão.

Como muitos, acreditamos na educação como caminho para transformar realidades injustas. Mas, que educação é possível para que homens e mulheres saiam da condição de imersão e desvendem os emaranhados míticos que os envolvem e lhes impedem de desenvolver sua humanidade, sendo pensadores críticos e criadores, capazes de produzir cultura e possibilitar melhores condições de vida para si e seus pares? Que caminhos percorrer para superar esse estado de opressão e serem livres para decidir autonomamente, valorizando o diferente e entendendo o conflito como fundamental para o avançar da humanização?

Neste sentido, a práxis - ação/reflexão - em outras palavras, escola e trabalho, é essencialmente importante para que sujeitos superem o estado de objetos e de dependência para se constituírem em homens e mulheres críticos e criativos, isto é, sujeitos históricos e, portanto, culturais, em processo de humanização permanente, ao longo da vida. Contudo, embora a relação do fazere do pensar seja um ganho, há a necessidade de um terceiro elemento, a cultura de paz, que traz a dimensão do sentir e medeia os conflitos que são imanentes aos humanos e suas relações; logo, é o motor para construção da cultura, sem a qual não há humanização. De tal modo, os conflitos também podem gerar estados disruptivos quando não mediados pela cultura de paz, levando ao extermínio daqueles que pensam e agem diferente e impedindo que as soluções ocorram justa e democraticamente.

Diante deste problema concreto e tendo identificado a relações entre os principais elementos que o constitui, esta investigação teve como objetivo perceber relações e equivalências dos temas geradores trabalho, escola e paz e suas pertinências para a humanização dos interlocutores da pesquisa. Para este intento, lançou-se mão de metodologia qualitativa, orientada por princípios da pesquisa participante, tendo como técnica o círculo de cultura e um roteiro aberto, além de gravador digital para conversas previamente autorizadas. Para auxiliar didaticamente nas discussões, utilizamos um objeto artístico, neste caso, uma obra de arte de Tarsila do Amaral, “Abaporu". Para as teorizações, o principal autor mobilizado foi Freire (2015), defensor do círculo de cultura, adepto dos temas geradores e em método colaborativo, como o da pesquisa participante. 


\section{CARACTERIZAÇÃO METODOLÓGICA DA PESQUISA}

O percurso metodológico deste trabalho é orientado pelo que recomenda Freire (2015) em seu livro "Pedagogia do oprimido", no que concerne a aspectos colaborativos entre os sujeitos através do círculo de cultura, tendo como objetivo estimular a expressividade dos interlocutores, tal como exposto pelo professor Ernani Maria Fiori, no prefácio da referida obra:

[...] A rigor, não se ensina, aprende-se em "reciprocidade de consciências"; não há professor, há um coordenador, que tem por função dar as informações solicitadas pelos respectivos participantes e propiciar as condições favoráveis à dinâmica do grupo, reduzindo ao mínimo sua intervenção direta no curso do diálogo. (FREIRE, 2015, p. 15).

Dessa maneira chegamos aos temas geradores que nos auxiliam na compreensão e em um olhar mais apurado sobre a completude da realidade, de forma desmitificada. Pois, segundo Freire (2015, p. 133),

[...] Está faltando aos homens uma compreensão crítica da totalidade em que estão captando-a em pedaços nos quais não reconhecem a interação constituinte da mesma totalidade, não podem conhecê-la. E não o podem porque, para conhecê-la, seria necessário partir do ponto inverso. Isto é, lhes seria indispensável ter antes a visão totalizada do contexto para, em seguida, separarem ou isolarem os elementos ou as parcialidades do contexto, através de cuja cisão voltariam com mais claridade à totalidade analisada.

Nesse sentido, partimos do material produzido através de roda de conversa, que coube saber os motivos de terem desistido dos estudos quando mais jovens, do contexto em que se encontram e de seus sonhos. A partir dos relatos dos interlocutores, sintetizamo-los em temas geradores, para assim pensarmos esta mesma realidade; a ela voltarmos com maior criticidade; e nela podermos agir mais conscientemente. Para Freire (2015, p. 134) é:

[...] A investigação do tema gerador, que se encontra contido no 'universo temático mínimo' (os temas geradores em interação), se realizada por meio de uma metodologia conscientizadora, além de nos possibilitar sua apreensão, insere ou começa a inserir os homens numa forma crítica de pensarem seu mundo.

A compreensão da realidade permite aos sujeitos condições para que pensem de maneira mais alargada e crítica, proponham outras maneiras de fazer, pois as codificações "são objetos cognoscíveis, desafios sobre que deve incidir a reflexão crítica dos sujeitos descodificadores" (FREIRE, 2015, p. 151). Este avançar dialético habilita os sujeitos para a compreensão de sua realidade, de modo que "aquele em que, analisando sua própria realidade, percebam sua percepção anterior, do que resulta uma nova percepção da realidade distorcidamente percebida" (p. 151).

Freire (2015) trata de níveis de percepção, pois o sujeito pode ter menor ou maior capacidade de compreensão sobre sua realidade, podendo intervir mais ou menos sobre o contexto em que vive de maneira crítica e criativa. "Por isso é que, embora as 'situações-limite' sejam realidades objetivas e estejam provocando necessidades nos indivíduos, se impõe investigar, com eles, a consciência que delas tenham" (p. 148).

Portanto, tão importante quanto partir das vivências dos sujeitos, para percebê-las criticamente, é também respeitar os níveis de percepção que possuem os sujeitos sobre a realidade onde se encontram, de modo que não apareça "de um lado, seu núcleo temático demasiado 
explícito; de outro, demasiado enigmático” (FREIRE, 2015, p. 151). Assim, o pesquisador não só deve "ouvir os indivíduos, mas desafiá-los cada vez mais, problematizando, de um lado, a situação existencial codificada e, de outro, as próprias respostas que vão dando aqueles no decorrer do diálogo" (p. 157).

Sob esses princípios, os relatos compartilhados pelos participantes permitiram pensar os elementos que poderiam ser sintetizados representativamente, problematizando todo o processo oportunamente, tendo como suporte um objeto artístico, a obra de Tarsila do Amaral, de 1928, "Abaporu", para incitar as discussões e ampliar a compreensão sobre os temas geradores, de modo a manterem neles a atenção e foco dos interlocutores.

Assim foi feito, porque:

[...] A investigação do pensar do povo não pode ser feita sem o povo, mas com ele, como sujeitos de seu pensar. E se seu pensar é mágico ou ingênuo, será pensado o seu pensar, na ação, que ele mesmo se superará. E a superação não se faz no ato de consumir ideias, mas no de produzi-las e de transformá-las na ação e na comunicação. (FREIRE, 2015, p. 141).

Freire (2015) afirma que "dizer a palavra não é privilégio de alguns, mas direito de todos" (p. 109). Palavra que só ganha sentido, se relacionada à práxis. A palavra quando dita reflete o pensar e o agir. Por isso mesmo diz:

[...] O que se pretende investigar, realmente, não são os homens, como se fossem peças anatômicas, mas o seu pensamento-linguagem referido à realidade, os níveis de sua percepção desta realidade, a sua visão do mundo, em que se encontram envolvidos seus "temas geradores" (FREIRE, 2015, p. 122).

Por isso a necessidade de utilização de métodos que incentivem a pronúncia dos interlocutores e, dessa maneira, possam ir desvelando a realidade e tomando consciência de si e do outro e nela intervir crítica e criativamente de maneira dialógica.

\section{TRABALHO E ESCOLA: EQUILÍBRIO ENTRE AÇÃO E REFLEXÃO}

No decorrer da pesquisa, sugerimos um exercício que incentivasse os interlocutores a rememorar os motivos de não terem continuado com os estudos, a situação em que se encontravam atualmente e sobre seus sonhos (Tabela 1), para assim sintetizarmos essas discussões em temas geradores e refletir sobre seus significados.

Tabela 1: Perfil dos interlocutores

\begin{tabular}{|c|l|l|l|l|}
\hline Nome & Idade & $\begin{array}{c}\text { Principal motivo } \\
\text { pelo qual } \\
\text { interromperam os } \\
\text { estudos }\end{array}$ & Ocupação atual & $\begin{array}{l}\text { Principal motivo pelo qual voltaram } \\
\text { a estudar }\end{array}$ \\
\hline Silva & 59 anos & Trabalho & Mecânico & Aprender a ler e a escrever \\
\hline Ferreira & 27 anos & $\begin{array}{l}\text { Separação dos } \\
\text { pais }\end{array}$ & Sem ocupação & Trabalhar \\
\hline Pereira & 42 anos & Trabalho & Sem ocupação & Trabalhar \\
\hline Alves & 40 anos & Trabalho & Sem ocupação & Trabalhar \\
\hline
\end{tabular}


DOI: $10.12957 /$ teias.2021.59773

\begin{tabular}{|c|l|l|l|l|}
\hline Morais & 29 anos & Trabalho & Sem ocupação & Trabalhar \\
\hline Costa & 34 anos & Trabalho & $\begin{array}{l}\text { Ajudante de } \\
\text { pedreiro }\end{array}$ & $\begin{array}{l}\text { Melhores oportunidades de } \\
\text { trabalho }\end{array}$ \\
\hline Nunes & 45 anos & Trabalho & Pintor de casas & $\begin{array}{l}\text { Melhores oportunidades de } \\
\text { trabalho }\end{array}$ \\
\hline Sousa & 53 anos & Inacessibilidade & Diarista & $\begin{array}{l}\text { Melhores oportunidades de } \\
\text { trabalho }\end{array}$ \\
\hline Danta & 52 anos & Trabalho & Dona de casa & Aprender a ler e a escrever \\
\hline Monteiro & 54 anos & Casamento & Dona de casa & Aprender a ler e a escrever \\
\hline Santos & 37 anos & $\begin{array}{l}\text { Não houve } \\
\text { interrupção }\end{array}$ & $\begin{array}{l}\text { Professora da } \\
\text { EJA }\end{array}$ & Aperfeiçoar-se na docência \\
\hline
\end{tabular}

Fonte: Dados da pesquisa (2019).

Neste caso, foi distribuído aos interlocutores papéis em branco de diversas cores e pincéis coloridos para que escrevessem palavras-chave e dispusessem-nas no centro de maneira que todos pudessem observá-las. Realizando a atividade, a Santos destacou as palavras respeito, família e sonhos. "Por que que en coloquei sonhos? Porque é o que eles estão procurando. O que eles estão fazendo aqui, entendeu? É pra realizar os sonhos deles" (Santos).

A Sousa destacou as palavras sonhos, trabalho e escola:

Escola. Por que sem escola pra onde é que nós vamos? (...). Então muitas coisas já me empatou devido não ter estudo. (...). Se não, eu não tava no que tô hoje. Então acho que é assim, a escola, primeiramente Deus, segundo você tem que estudar (...). Tudo depende do estudo. (Sousa).

O Morais resumiu o encontro anterior em respeito, trabalho e paz:

Hoje em dia as pessoas tá no trabalho e às vezes o horário não bate se você vai pra escola. Às vezes você fica sem saber se vai pra escola ou vai trabalhar. E para não perder o emprego, deixa de ir pra escola porque tem que trabalhar. Tem que escolher um ou outro. E a gente depende do trabalho para sobreviver. Aí não tem jeito. (Morais).

Já o Silva salientou as palavras acreditar, amor e oportunidade: "Às vezes muitas coisas se você não tiver oportunidade (...) você não arruma, não consegue. (...). Se você não tiver oportunidade de tá aqui, às vezes você não concluísse o seu trabalho" (Silva).

Para o Ferreira mereceram menção as palavras dedicação, paz e amor. A dedicação "pra conseguir as coisas. Conseguir ir crescendo" (Ferreira). Para a Monteiro ganharam importância as palavras amor, sala e união:

A sala de aula pra mim (...) é um sonho eu tá aqui. Que eu quis, sempre quis. Estudar. Eu quero aprender. Eu quero chegar num lugar e saber falar. É... Escrever alguma coisa sem ter medo, sem ter vergonha, sem errar. É o meu sonho fazer as coisas, sabe? Estudar. Aprender mesmo. (Monteiro).

Os interlocutores destacaram também aspectos relacionados à união e deram exemplos significativos, próprios da realidade. O Silva diz que: "Porque se ocê pensar só nocê, como é que você vai viver? (...) Porque sozinho ocê não vive. Por que o que adianta nós tá aqui sem a professora? O que adianta a professora tá aqui sem nós? (Silva). 
De igual modo, a Monteiro falou algo que lhe tinha acontecido bem recentemente. "Ontem ele [um professor da EJA] passou uma tarefinha, não foi?. Eu falei 'professor eu não dou conta de ler'. Ai ele falou 'dá sim'. 'V ocê vai dar conta'. Ai eu falei... 'não dou conta'.... Ai todo mundo falou 'então vamos ler juntos'. Isso é união". (Monteiro).

Ela diz também, a partir de suas experiências, sobre a importância do amor:

[...] Professores maravilhosos. (...). Muito educado, muito gentil com os alunos. Deixa a gente à vontade. Isso é muito importante pra gente, né? O que a gente... você sai de casa pra estudar, principalmente os primeiros dias. Você fica com vergonha. Não sabe como vai ser recebido. Como é que vai ser. Aí você chega. Não... É completamente diferente. É, tem um carinho imenso pela gente. Trata a gente com amor. Então isso deixa a gente à vontade. Faz. Faz com que você sente vontade todo dia. Você toma banho, hoje eu vou. Mesmo cansada. (Monteiro).

Para Silva:

[...] O amor é uma palavra muito forte. $\mathrm{O}$ amor, você tem que começar a se amar. Você ama o próximo. Se você ama o seu próximo, você ama a si mesmo. A vida vai ser... Como no nosso país. A gente tá precisando muito de amor. (...) Tudo. A gente é uma corrente. Querendo ou não querendo a gente forma um elo. (...). Essa menina [Santos] aí, ó. Cê vê, ajuda a gente. Cê vê... Ela dá chance. Ela não intimida a gente hora nenhuma" (Silva).

Seguindo com as atividades, os interlocutores, em conjunto com o pesquisador, puderam relacionar as palavras dispostas no centro do círculo. Entre as palavras constavam ESCOLA, TRABALHO e PAZ, selecionadas para serem os referenciais, visto que condensavam as discussões, sendo as demais relacionadas a estas três. As outras palavras foram: oportunidade, dedicação, sonhos, sala, união, amor, respeito e acreditar, como elencadas pelos interlocutores acima.

Com os temas geradores em vista, expôs-se a obra "Abaporu" de Tarsila do Amaral (Figura 01). Com o objetivo de alargar a concepção sobre os apontamentos feitos até o momento, os sujeitos puderam juntos construir sentidos para o objeto artístico, a partir da realidade vivenciada pelo grupo. Depois de exposta a pintura digitalizada em tamanho grande em uma TV, método inspirado em Ana Mae Barbosa (1995), e feitos breves apontamentos contextuais sobre a obra e a artista, os participantes puderam observá-la por inteiro e iniciar descrevendo e narrando suas percepções sobre a obra com liberdade. 
Figura 1: “Abaporu” de Tarsila do Amaral

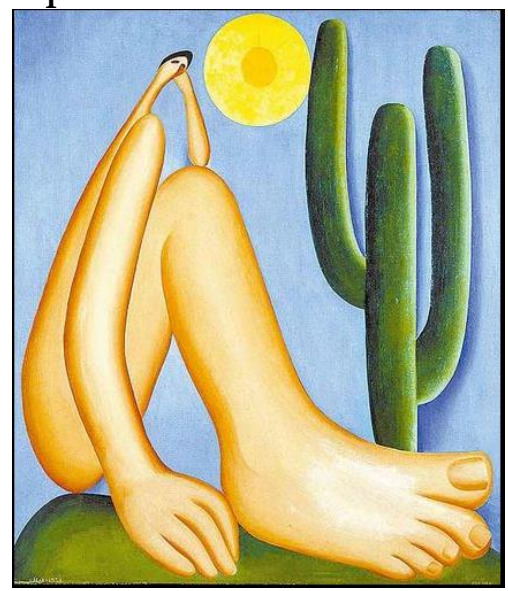

Fonte: Wikipedia.

Inicialmente, os participantes reagiram com estranhamento e com certo espanto. Mas essas reações foram servindo como motivadores para que se entusiasmassem e expusessem suas impressões. Os interlocutores demonstraram não conhecer a obra e as primeiras impressões se concentraram em aspectos descritivos, mas logo avançaram para análises dos possíveis sentidos que a obra poderia ter.

Como dito, partiu-se de elementos descritivos da obra. A Santos ao ser questionada sobre o que via, disse: "Eu enxergo um pé. Parece que a pessoa tá descalça e me parece que deve ser do sertão (...) Por causa do pé de (...) mandacaru. Que geralmente é na seca que tem ele” (Santos).

Seguindo com as descrições, a Monteiro falou que as condições físicas eram de: "Muito sol. Quente (...). Que é... nesse lugar, na minha maneira de expressar, tá num lugar quase deserto. E tem muito sol, então é muita seca. Aí onde essa pessoa tá aí que tem esse tipo de planta aí, geralmente é no Nordeste" (Monteiro). A Santos completa dizendo "A pessoa com pé no chão (...) num lugar sofrido" (Santos). O Ferreira disse que pensou se tratar de "um indio (...) pelo nome".

"Mas o que ele quis dizer com uma parte do corpo bem destacado e a outra...", menciona o Nunes. "De andar descalço" emendou a Monteiro. O Nunes insiste: "Será (...) porque devido o lugar ser pacato, pensa mais pouco? E a cabȩ̧a ficou tão pequena?" (Nunes). O Morais trouxe outra possibilidade "às vežes pode ser também uma pessoa que às vezes pode ter problema de saúde também, né? Uma parte do corpo maior que a outra. Outra parte menor" (Morais). O Silva também trouxe outra perspectiva: "às vezes pode ser igual... você tira uma foto daqui pra baixo, tira mais de longe, é a mesma pessoa" (Silva). A Santos, no entanto, retoma a perspectiva iniciada pelo Nunes:

[...] também (...), poderia ser o contexto do pé e mão ser maior como o Nunes tava perguntando, porque no lugar de estudar... entendeu? Trabalhou muito. Então quem trabalha muito, geralmente os pés e as mãos, entendeu? Eu acho que tá retratando deve ser isso também. E não estudou. Então, quer dizer... isso quer dizer, né? Intelectualmente ele não cresceu, mas cresceu em trabalho. (Santos).

O Nunes reforçou: "Deve ter um significado, o desenho de uma parte do corpo ser mais destacada e o outro mais pequena, né?". E também reforça elementos já destacados pelos colegas: "O mandacaru já significa o deserto, o sertão. O sol todo mundo sabe que lá é castigante". Diante de tal situação, a Monteiro pergunta: "e agora, o que que eu vou fazer?”. 
O Morais potencializa a discussão em torno do estudo e do trabalho: "Pode ser também uma pessoa que às vezes trabalhou muito com o corpo, né? E menos com a mente. Poderia não ter oportunidade de trabalhar com a mente" e problematiza: "Hoje em dia não adianta você trabalhar com os bracos, com o corpo e não trabalhar com a mente. Seria mais trabalhar com a mente que com o corpo" (Morais). Ao ser questionado sobre esse ponto de vista, ele responde: "trabalhando com a mente pode ser num espaço pequeno, mas você consegue produحir mais" (Morais). Novamente questionado sobre os efeitos inversos, ele enfatiza: "tendo a cabeça, pé e mão quem manda é a cabeça, quem manda no corpo é a cabeça, é a mente" (Morais).

Após estas considerações, os interlocutores fizeram conexão com suas experiências. Em humor gracejo, o Ferreira fala que: "Nós sofre igual passarim em mão de minino" (Ferreira). A Monteiro emenda:

O meu pai falava assim que as pessoas... fala assim... ele já doente, ele falava assim "procura trabalhar mais com a cabeça do que com os braços e as pernas". Eu não entendia, como até hoje eu fico me perguntando. Eu entendo um pouco, mas né, eu pequena, meu pai 'procure trabalhar mais com a cabeça do que com os braços e as pernas'. (...). Eu devia ter trabalhado mais com a cabeça do que com os braços e com as pernas. Eu não tenho nada. Aí hoje eu já entendo um pouco. Que ele sofreou muito, trabalhou muito. (...). Isso aí é um pouco assim... é um pouco... a pessoa, sei lá, acho que aí ele tá pensando assim 'eu trabalhei tanto... oh meu Deus! Eu trabalhei tanto, e agora? Plantei e a chuva não veio. Só sol'. Assim, na minha maneira de pensar, né. Tem esse lado também. (Monteiro).

\footnotetext{
A Sousa reafirma: "É o mesmo que a Monteiro acabou de falar agora é o que eu ia falar. Que as pessoas cansam, né?" (Sousa).

O Silva reflete dizendo que:

É uma pessoa que sofreu muito. Às vezes sofreu. E não teve uma palavra que nós disse agora, uma oportunidade de sair do lugar, de tomar uma decisão, de... ele tá pensativo lá né? Não sabe se vai ou se fica. Às vezes... se não tem ninguém para dá uma oportunidade pra ele. Por isso que às vezes ele pode tá escabreado daquele jeito. É. Uma oportunidade, né? Que as pessoas às vezes não dá pro outro (Silva).
}

Assim, a partir da obra de Tarsila do Amaral, ofereceu-se aos estudantes oportunidade de fruição e dela poderem denotar aspectos pertinentes ao fazer e pensar (ação e reflexão), questionando a relação entre trabalho e escola, quando estes são vivenciados assimetricamente, e refletindo sobre seus motivos e consequências.

Para Freire (2015) "os homens que, através de sua ação sobre o mundo, criam o domínio da cultura e da história (...) práxis que sendo reflexão e ação verdadeiramente transformadora da realidade, é fonte de conhecimento reflexivo e criação" (p. 127). Contudo, quando se é reduzido a condição de animais, significa que, mesmo com ânimo, não pode criar, porque só repete o que outros dizem, porque perdeu a capacidade de pensar criticamente e apenas obedece.

Assim, explica Paulo Freire (2015): “Os homens são seres de práxis. São seres do quefazer, diferentes, por isto mesmo, dos animais, seres do puro fazer. Os animais não 'admiram' o mundo. Imergem nele" (p. 167). No "esforço revolucionário de transformação radical destas estruturas não pode ter, na liderança, homens do quefaz̧er e, nas massas oprimidas, homens reduzidos ao puro faz̧er” (FREIRE, 2015, p. 168), sendo o quefažer teoria e prática, ação e reflexão.

A inferiorização a que se encontra o oprimido é decorrente de um processo de colonização, posto que: 
[...] Todo ato de conquista implica um sujeito que conquista e um objeto conquistado. O sujeito da conquista determina suas finalidades ao objeto conquistado, que passa, por isto mesmo, a ser algo possuído pelo conquistador. Este, por sua vez, imprime sua forma ao conquistado (FREIRE, 2015, p. 186).

Ao que chama Freire (2015) de invasão cultural, que "é a penetração que fazem os invasores no contexto cultural dos invadidos, impondo a estes sua visão do mundo, enquanto lhes freiam a criatividade, ao inibirem sua expressão" (FREIRE, 2015, p. 205). Neste caso, "os invasores modelam; os invadidos são modelados. Os invasores optam; os invadidos seguem sua opção. (...). Os invasores atuam; os invadidos têm a ilusão de que atuam, na atuação dos invasores” (p. 205).

Pois, "a única forma de pensar certo do ponto de vista da dominação é não deixar que as massas pensem" (FREIRE, 2015, p. 177). Só fazer estagna e tanto mais enfraquece quem já se encontra em condição de vulnerabilidade, de oprimido, enfatizando uma "visão localista dos problemas e não visão deles como dimensão de uma totalidade" (p. 191).

O interesse dos opressores em relação ao oprimido não é aquele que não seja apenas o de dominar e "só interessa saber como pensam os invadidos seu próprio mundo para dominá-los mais" (FREIRE, 2015, p. 206). A invasão cultural tem como finalidade a dominação e esta acontece tão mais facilmente quando os invadidos perdem sua humanidade, passando da diversidade para a homogeneização, moldados aos padrões do opressor. Pois "quanto mais mimetizados fiquem os invadidos, melhor para a estabilidade dos invasores" (p. 206).

Assim, "quanto mais se acentua a invasão, alienando o ser da cultura e o ser dos invadidos, mais estes quererão parecer com aqueles: andar como aqueles, vestir à sua maneira, falar a seu modo" (FREIRE, 2015, p. 206), perdendo sua originalidade para serem imitadores; perdendo sua verdade, para serem falsos; perdendo sua capacidade de criação, para serem reprodutores; perdendo, portanto, sua humanidade, agindo prescritivamente, deixando de produzir cultura, de produzir o novo e impedindo a própria história. Freire diz que "para haver desenvolvimento, é necessário que haja um movimento de busca, de criatividade, que tenha, no ser mesmo que o faz, o seu ponto de decisão" (p. 217). Por isso o "esforço de propor aos indivíduos dimensões significativas de sua realidade, cuja análise crítica lhes possibilite reconhecer a interação de suas partes" (p. 134).

\section{Trabalho e escola entremeados pela cultura de paz}

A invasão cultural se assemelha ao que diz Johan Galtung (2003) sobre violência cultural. Segundo o mesmo autor, existem três tipos de violência: a direta, a estrutural e a cultural. Significa dizer que:

[...] Para lá da violência pessoal ou direta, existe a violência estrutural, resultante da desigualdade de poder e da injustiça social. E ainda a violência cultural, aquela que se traduz no sistema de normas e comportamentos que legitimam socialmente as duas anteriores. (PUREZA, 2000, p. 39).

Para a superação desta condição que traz prejuízos a todos, Freire (2015) defende a pedagogia do oprimido, que possui dois momentos:

[...] O primeiro em que os oprimidos vão desvelando o mundo da opressão e vão comprometendo-se, na práxis, com a sua transformação; o segundo, em que, transformada a realidade opressora, esta pedagogia deixa de ser do oprimido e 
DOI: $10.12957 /$ teias.2021.59773

passa a ser a pedagogia dos homens em processo de permanente libertação. (p. 57).

A pedagogia libertadora lança mão do diálogo que propõe Freire (2015) e que está de acordo com o que sugere Galtung (2003a, p. 02), visto que "a paz é a condição que permite aos conflitos serem transformados de maneira criativa e não-violenta". Para a transformação do conflito, segundo Galtung (2003a, p. 04),

[...] Em primeiro lugar, é preciso empatia em relação a todas as partes - não a versão barata do tipo: "Como eu me sentiria se estivesse no lugar deles?", mas no sentido de "como é realmente estar no lugar deles?". Em segundo lugar, é preciso limitar-se à ação não- violenta, entre outros motivos, para quebrar os ciclos de "violência gera violência". Em terceiro, é necessário usar de criatividade para transcender as contradições. O problema é: de onde tiraremos estas "matérias primas" escassas e preciosas? Tiraremos de uma cultura de paz, visto que estes são os três componentes principais de tal cultura.

Sabendo que "a cultura é um aspecto simbólico da existência humana. A cultura é representação, através de símbolos, em geral visuais" (GALTUNG, 2003a, p. 01). De acordo com Hall (2016), representação, sinteticamente, "diz respeito à produção de sentido pela linguagem", ou seja, "produzir uma semelhança de algo na nossa mente ou em nossos sentidos. (...) significa simbolizar alguma coisa" (p. 32). Logo, possibilita ao homo sapiens "um mapa de realidade virtual que serve como guia para a realidade real" (GALTUNG, 2003a, p. 02).

Nesse sentido, paz representa "a ausência de violência de todos os tipos - direta (física e também verbal), estrutural, cultural - dirigida contra o corpo, a mente ou o espírito de um outro ser, humano ou não" (GALTUNG, 2003a, p. 02). Desta forma, "a paz se torna o contexto (interno e externo) que propicia uma forma construtiva de lidar com o conflito" (GALTUNG, 2003a, p. 02), que por sua vez, significa "contradicción, es decir, objetivos que son incompatibles. Pero um conflito suele tener también componentes de actitud y comportamento. Y essas actitudes están generalmente condicionadas por el subconsciente colectivo" (GALTUNG, 2003b, p. 04). Por isso Galtung (2003a) traz uma provocação: "diga-me como se comporta num conflito e te direi qual o seu nível de cultura de paz".

A relação dos elementos que favorecem e constroem a humanização mostram que o conhecer leva a um melhor fazer e que estes se retroalimentam, de modo que também não podem se separar do saber ser e do saber conviver juntos (DELORS, 2006). Portanto, o fazer precisa do conhecer e ambos necessitam de o saber ser e conviver. Pois, de outro modo, criaria um atravancamento no avançar do ser mais e não haveria nesse entremeio a práxis da cultura de paz. Decidir entre estudar ou trabalhar não é o mais adequado, como expõe o Morais, um de nossos interlocutores, é necessário que se garanta oportunidades e condições para que o trabalho e a formação sejam paralelamente constantes na vida dos sujeitos.

De acordo com o exposto, outro aspecto que poderia ser levantado é a democracia, e quem nos diz sobre ela é Edgar Morin (2011). Os elementos destacados pelos nossos interlocutores, para proliferarem e terem vida longa, clamam por um contexto democrático. "A democracia supõe e nutre a diversidade dos interesses, assim como a diversidade de ideias" (p. 95). Além de que a "democracia favorece a relação rica e complexa indivíduo-sociedade, em que os indivíduos e a sociedade podem ajudar-se, desenvolver-se, regular-se e controlar-se mutuamente" (p. 94).

Percebe-se que um aspecto leva a outro num processo que é também cumulativo. Sem a democracia, e, portanto, sem a diversidade e respeito às diferenças, um tanto de outras 
características próprias da liberdade, deixam de existir, constituindo um sistema de opressão, de ditadura, num sistema autoritário, que "colonizam os indivíduos" (FREIRE, 2015, p. 95).

Segundo Oliveira (2017) "os conflitos são inerentes às relações sociais e, como tal, não podem ser negados e nem sufocados, mas sim transformados de forma criativa e não violenta" (p. 163). Por isso "é preciso proteger a diversidade de ideias e opiniões, bem como a diversidade de fontes de informação e de meios de informação (impressa, mídia), para salvaguardar a vida democrática" (MORIN, 2011, p. 95).

Nesse sentido, "a democracia é mais do que um regime político; é a regeneração contínua de uma cadeia complexa e retroativa: os cidadãos produzem a democracia, que produz cidadãos" (MORIN, 2011, p. 94), ou seja, é um ambiente de liberdades. Na democracia, o fazer e o pensar considera o ser e o conviver juntos (DELORS, 2006). Pois, "o indivíduo é cidadão, pessoa jurídica e responsável; por um lado, exprime seus desejos e interesses; por outro lado, é responsável por sua cidade e solidário com ela" (MORIN, 2011, p. 95).

Nesse contexto, outro aspecto levantado por Morin (2011) é a compreensão. Justamente porque exige "abertura, simpatia e generosidade" (p. 82). Num ambiente democrático, no qual a diversidade e as diferenças são constantes, a compreensão torna-se "a arte de viver que nos demanda, em primeiro lugar, compreender de modo desinteressado" (p. 86). A compreensão está de acordo com os elementos apontados pelos nossos interlocutores, visto que se trata de uma característica importante para o saber ser e saber conviver, ou seja, optar pela cultura de paz. Para tanto, é necessário exercitar a introspecção, que exige um constante autoexame. Dessa forma, ao sabermos "compreender antes de condenar, estaremos no caminho da humanização das relações humanas" (p. 87).

Morin (2011) toca em outro aspecto fundamental do ser humano, a comunicação, ao afirmar que sem a compreensão a comunicação inexiste, pois, a compreensão é meio e fim da comunicação. Nesse sentido, ele recomenda que "o desenvolvimento da compreensão necessita da reforma planetária das mentalidades; esta deve ser a tarefa da educação do futuro" (p. 91).

A comunicação pressupõe diálogo e este, segundo Freire (2015), tem como fundamento o amor, sendo que "o amor é ato de coragem, nunca de medo, o amor é compromisso com os homens" (p. 111). Virtude esta que requer humildade, porque "não há (...) diálogo, se não há humildade" (p. 111).

Nesse sentido, pode-se dizer que, ao pronunciar as palavras trabalho, acreditar, escola, oportunidade, dedicação, sonhos, união, família, paz, amor e respeito, os interlocutores põem-se em direito de dizer a palavra (FREIRE, 2015). Pondo-se em condição de homens e mulheres, de seres humanos. Segundo Freire, "o diálogo, como encontro dos homens para a "pronúncia" do mundo, é uma condição fundamental para a sua humanização" (p. 185). Um dizer que é coerente com a prática, pois derivante da própria realidade de quem diz. Juntos podem dizer, porque confiantes um no outro tornam-se "cada vez mais companheiros na pronúncia do mundo" ( $p$. 113).

A colaboração não pode acontecer sem a confiança. Da mesma forma que o diálogo não acontece sem o amor, que requer também humildade. Elementos que contribuem para um jeito diferente daquele praticado pelo opressor, que impede do outro dizer, devido serem postos em condição de incapazes, porque oprimidos, atribuindo a si o direito de dizer a palavra do outro e assim exercer direitos sobre aquele que é impedido de dizer. Sem a pronúncia não há diálogo. Não havendo diálogo, não há amor, não há humildade, não há confiança e colaboração. Deixa de ser cultura de paz para existir violência.

Portanto, o que parece simples, como de fato é, pois é humildade, o fato de os interlocutores pronunciarem palavras de libertação, de humanização, é grande ato de coragem, de 
rompimento de um sistema de opressão, ou seja, de violência, que por muito tempo vem exercendo poder na vida de muitos sujeitos que por muito tempo foram emudecidos e impedidos de pensar suas realidades de pensar seus fazeres.

\section{CONSIDERAÇÕES FINAIS}

O discorrer da pesquisa orientou-se tendo em vista o trabalho, a escola e a paz. Estas três categorias (temas geradores) foram se constituindo no transcorrer das discussões entre teóricos, objetivos desta pesquisa participativa e a realidade dos interlocutores. A base deste artigo encontrase no fazer, no pensar e no sentir, entremeado pela cultura de paz. Vimos que a ação, a reflexão e a cultura de paz relacionam-se interdependentemente. De modo que na ausência de um, a humanização fica impedida de avançar, podendo até retroceder, neste instante caracterizando-se como violência.

Os participantes da pesquisa são estudantes da Educação de Jovens e Adultos (EJA). Significa dizer que foram de algum modo impedidos de desenvolverem suas potencialidades de forma sistemática e oficialmente legítima. A partir do primeiro encontro da pesquisa, percebemos que o principal motivo de voltarem a estudar agora adultos é exatamente a razão pela qual deixaram de estudar em idade mais jovem, isto é, o trabalho. Estão à procura de conhecimento técnico para desenvolver atividades mais complexas ao que eles já fazem e para legitimar, através de um certificado, suas profissões, ou ainda angariar um emprego.

Embora saibamos a importância do conhecimento técnico, queríamos avançar para além desta questão, visto que este pode ser fornecido por uma educação reprodutora, conteudista, isto é, bancária. O saber técnico, tal qual, serve para cumprir com tarefas, para reproduzir, para repetir, seguir comandos. O conhecimento técnico em si não é condenável, precisamos dessas habilidades para o trabalho. No entanto, entendemos que dessa maneira, os sujeitos se assemelham a animais irracionais, porque só reproduzem, cumprindo com a vontade de terceiros e se assemelhando a objetos, porque são manipuláveis. Nisso consiste um problema, porque nem animais e nem objetos produzem cultura. Tanto animais quanto objetos são a-históricos, são aculturais.

Podemos questionar que nenhum homem ou mulher pode chegar de fato a estes estados de coisas e de bichos. Concordamos que realmente trata-se de uma impossibilidade. Contudo, sabemos que homens e mulheres, além de avançar para a humanidade, podem retroceder também. Consideramos que o declínio constitui um movimento que é nocivo e acontece por alguma razão que pode estar envolta a opressão, à violência, de injustiças, portanto.

Neste caso, entendemos que a educação não deve ser bancária, mas libertadora. Que proporcione aos educandos e educadores, além do fazer, também o pensar. Para tanto deve ser problematizadora, de modo a fazer o movimento progressivo à humanização dos sujeitos, contribuindo para a construção de um pensamento crítico e um fazer criativo.

Antes, os interlocutores da pesquisa deixaram os estudos para trabalhar e, atualmente, por falta de trabalho, voltaram a estudar. Este vai e vem parece fazê-los cansar, visto que, quando estão à procura de algo, deixam de ter outro, sendo que ambos são importantes juntos e não separados. No decorrer dos encontros, percebemos que trabalho e estudo, em outros termos, significam ação/reflexão. Sem um, o outro encontra-se incompleto, impossibilitando o movimento dialético. Portanto, inviabilizando o avançar. Estudo e trabalho, como a prática e o discurso, são indissociáveis, constituindo o próprio sujeito e que devem ser compreendidos como processo ao longo da vida, constante e initerruptamente. Ou seja, nem só trabalho, nem só estudo; nem só ação, nem só reflexão; nem só criticidade, nem só criatividade, mas ambos pareados e imbricados. 
A partir do referencial teórico, percebemos que este movimento dialético da ação e reflexão, escola e trabalho, criticidade e criatividade, não garante que a violência não aconteça. Por isso deve estar baseada exatamente em seu contrário, a cultura de paz. Formando dessa maneira a dialética da ação/reflexão, entremeada por sentimentos e atitudes que prezam pelo diferente, tendo em vista o conflito como imanente ao ser humano e motor para o avançar. Cultura de paz pode ser entendida sinonimamente como democracia.

Ser crítico e criativo, isto é, ação/reflexão - trabalho/escola, e agir e sentir a partir da cultura de paz, é considerar o que apregoa os quatro pilares da educação: aprender a conhecer, a fazer, a ser e a viver juntos. Podemos relacionar o conhecer à reflexão, escola e criticidade; o fazer à ação, trabalho e criatividade; e o ser e viver juntos congregam os princípios da cultura de paz. Entendese que o ser e o conviver pressupõem duas partes, o eu e o tu, que dialogam, caracterizando, portanto, a existência da cultura de paz. Nesse sentido, o diálogo exige que os sujeitos envolvidos tenham desenvolvidos em si as competências do ser e do conviver. Portanto, não basta apenas o saber e o fazer, é necessário o conhecer-se e o conviver, que quer dizer capacidade de diálogo, de poder exercer a cultura de paz.

Como dito, para haver diálogo é necessário ter dois sujeitos que podem ser tidos como o eu e o tu. Desse diálogo resulta o nós. O nós é diferente do eu e do tu, ou seja, o resultado do diálogo gera algo novo, que não quer dizer meramente a soma das partes. O diálogo, portanto, permite a criação do novo. O novo, então, só pode ser gerado a partir de duas partes que são diferentes que, num embate, permite a criação. Este novo, ou seja, a criação é a própria cultura, fato que somente os seres humanos são capazes de realizar e que o fazem melhor em condições democráticas, isto é, a partir da cultura de paz, pois diferente da violência, entende que o outro e o conflito são importantes para a humanização de si e do outro, questionamento que deve emergir principalmente de quem sofre. Por isso que este movimento é libertador tanto para o oprimido como para o opressor que se colocam em caminhar de libertação.

Neste sentido, podemos arriscar em dizer que a opressão/violência é "estúpida", e seu egoísmo atravanca o processo próprio da humanização, da cultura. Também é nociva para todos, inclusive para opressores. Pois, quanto mais sujeitos livres, mais podem contribuir para soluções que abarcam a todos, como o desiquilíbrio ambiental, o processo migratório, a inteligência artificial e tantas outras questões que preocupam a humanidade.

Diálogo, este é o grande alcance que Freire nos mostra. O diálogo exige que ambos tenham a palavra, que ambos tenham criticidade, que ambos se comprometam em transformar criativamente realidades que impedem a humanização e o equilíbrio da natureza. Portanto, diálogo supõe que sujeitos nos mais diversos níveis de percepção da realidade são capazes de contribuir autonomamente com uma comunidade mais forte e coesa, refletindo na sociedade inteira. $\mathrm{O}$ diálogo exige que as relações sejam horizontalizadas e descentralizadas, para que todos possam participar do processo e se autoajudarem.

Nesse sentido, em uma sociedade mais equilibrada, as desigualdades se anulam, e a população vive mais consciente e confiante. Positivamente os impactos são imensos. Uma população com capacidade de decisão, de criação, é capaz de resolução de conflitos. Estes conflitos se apresentam de várias formas, em níveis simples aos mais complexos. $\mathrm{Na}$ autonomia, são capazes de pensar esta realidade e buscar soluções individuais e coletivas, tornando assim as comunidades mais saudáveis e unidas. Portanto, o equilíbrio entre o fazer, o pensar e o sentir são elementos que precisam estar pareados para que os sujeitos sejam capazes de realizar tarefas com liberdade.

\section{REFERÊNCIAS}


BARBOSA, Ana Mae. Arte-educação pós-colonialista no Brasil: aprendizagem triangular. Comunicação e Educação, São Paulo, v.2, p. 59 a 64, jan./abr. 1995.

DELORS, Jacques et al. Educação: um tesouro a descobrir. Relatório para a UNESCO da Comissão Internacional sobre Educação para o século XXI. 10.ed. UNESCO, MEC: Cortez, 2006.

FREIRE, Paulo. Pedagogia do oprimido. 59. ed. Rio de Janeiro: Paz e Terra, 2015.

GALTUNG, Johan. Paz. Cultural: Algumas Características. 2003a. Disponível em: http://www.palasathena.org.br/arquivos/conteudos/Paz Cultural Johan Galtung.pdf. Acesso em: 2 mar. 2020.

GALTUNG, Johan. Violência cultural. Bizkaia, Spain, Gernika Gogoratuz, 2003b.

HALL, Stuart. Cultura e representação. Rio de Janeiro: Ed. PUC-Rio: Apicuri, 2016.

MORIN, Edgar. Os sete saberes necessários à educação do futuro. Tradução de Catarina Eleonora F. da Silva e Jeanne Sawaya. São Paulo: Cortez; Brasília, DF, UNESCO, 2011.

OLIVEIRA, Gilberto Carvalho de. Estudos da paz: origens, desenvolvimentos e desafios críticos atuais. Ver. Carta Inter. Belo Horizonte, v. 12, n. 1, p. 148-172. Maio/2017.

PUREZA, José Manuel. Estudos sobre a paz e cultura da paz. Revista nação e defesa. Lisboa, n. 95/96, $2^{a}$ Série, p. 33-42, Outono-Inverno/2000.

Submetido em maio de 2021

Aprovado em outubro de 2021

\section{Informações dos autores}

Madson Pinto dos Santos

Universidade Federal do Tocantins

E-mail:madsonsantoscs@hotmail.com

ORCID: https://orcid.org/0000-0002-9407-2376

Link Lattes: http:// lattes.cnpq.br/2993535462869049

Rosária Helena Ruiz Nakashima

Universidade Federal do Tocantins

E-mail: rosaria@uft.edu.br

ORCID: http://orcid.org/0000-0001-7798-6363

Link Lattes: http://lattes.cnpq.br/1260810466635374 